\title{
Presunción de inocencia y estándar de prueba en el proceso penal: Reflexiones sobre el caso chileno
}

\author{
Sebastián Reyes Molina*
}

RESUMEN

Los estándares de prueba juegan un rol fundamental a la hora de determinar la decisión del juez, pues solo si son superados se puede tener por suficiente la acreditación de un hecho, y, al declararlo como probado, se es posible determinar si la presunción de inocencia ha sido derrotada. Esta operación intelectual debe ser explicitada en la motivación de la sentencia condenatoria. Consecuencia de esto es que los estándares de prueba sirven para impedir la arbitrariedad judicial a la hora de juzgar, debido a que controlan los criterios de decisión del juez delimitando el nivel de prueba que se debe alcanzar para que este pueda declarar por probado un hecho, evitando asi que se condene en base a la sola voluntad del juzgador. Luego, un estándar de prueba en el proceso penal juega, a nivel constitucional, un rol de garantía de la Presunción de Inocencia. Sin embargo, en nuestro ordenamiento jurídico, el estándar previsto por el legislador, está lejos de cumplir dicho rol.

Presunción de inocencia - estándar de prueba - más allá de toda duda razonable

\section{Presumption of innocence and standard of proof in criminal proceedings: Reflections on the Chilean case}

\begin{abstract}
The standard of proof plays an important role in the adjudication task, because only if the standard is exceeded we can say that a statement of fact has been proven. Only then, we can determine if the presumption of innocence is defeated. This intellectual operation must be expressed by the judge in the sentence. The consequence of this duty is that the standard of proof has the utility to prevent a judge's subjective decision at the time of the adjudication. And so, prevent a conviction based only in an arbitrary decision. Therefore in criminal law, a standard of proof, in a constitutional level, is a mechanism of protection of the presumption of innocence. Yet, in our legal system, this standard doesn't fulfill that task.
\end{abstract}

Presumption of innocence - standard of proof - beyond all reasonable doubt

* Licenciado en ciencias jurídicas y sociales, Universidad Austral de Chile. Correo electrónico: Sebastian. Reyes.Lex@gmail.com

Artículo recibido el 19 de diciembre de 2011 y aceptado para su publicación por el Comité Editorial el 26 de octubre de 2012. 


\section{Presunción de inocencia: Derecho constitucional DE DIMENSIÓN PROCESAL}

$\mathrm{E}$

n el Derecho Internacional Americano, la presunción de inocencia se encuentra reconocida tanto en la Declaración Americana de Derechos y Deberes del Hombre, aprobada en Bogotá el año 1948, en su disposición XXVI, como en la Convención Americana sobre Derechos Humanos, suscrita en San José de Costa Rica el 22 de noviembre de 1969, la cual en nuestro país se promulgó el 23 de agosto de 1990 y fue publicada en el Diario Oficial el 5 de enero de 1991. Esta convención en su artículo $8 \mathrm{~N}^{\mathrm{o}} 2$ dispone que "(t)oda persona inculpada de delito tiene derecho a que se presuma su inocencia mientras no se establezca legalmente su culpabilidad" ${ }^{\text {. }}$

Chile al suscribir dichos tratados pasa a incorporar a su ordenamiento jurídico las normas de estos, de acuerdo con lo establecido en el art. $5^{\circ}$ inc. $2^{\circ}$ de la Constitución Política de la República (en adelante CPR) ${ }^{2}$, las cuales constituyen, según lo dispuesto en el art. 5 inc. $1^{\circ}$ de la misma $^{3}$, un límite a la soberanía debiendo ser asegurados y promovidos por todas los órganos del Estado ${ }^{4}$.

Sin perjuicio de lo anterior, el hecho de que nuestra Carta Fundamental no consagre de forma expresa la presunción de inocencia no obsta que el legislador deba observarla como norma suprema, debido a que según lo dispuesto en el mencionado art. 5 inc. $2^{\circ}$ de la CPR debe entenderse incorporados a esta todos los tratados internacionales sobre derechos humanos ratificados por Chile que se encuentren vigentes ${ }^{5}$.

Se concluye entonces que la presunción de inocencia pasa a ser un Derecho Fundamental cuyo origen se encuentra en el bloque constitucional de derechos de acuerdo con el mandato preceptuado en el art. $5^{\circ}$ inc. $2^{\circ}$ de la $\mathrm{CPR}^{6}$, entendiendo por este, el conjunto de derechos de la persona asegurados por fuente constitucional o por vía del derecho internacional de los derechos humanos ${ }^{7}$.

${ }^{1}$ Cfr. Jara, J. "Principio de inocencia. El estado jurídico de inocencia del imputado en el modelo garantista del proceso penal"., Revista de Derecho Universidad Austral de Chile, Vol. X, No especial reforma procesal penal, 1999, Valdivia, p. 47.

${ }^{2} \mathrm{El}$ art. $5^{\circ}$ inc. $2^{\circ}$ de la CPR dispone: "Es deber de los órganos del Estado respetar y promover tales derechos, garantizados por esta Constitución, así como por los tratados internacionales ratificados por Chile y que se encuentren vigentes".

${ }^{3} \mathrm{El}$ art. $5^{\circ}$ inc. $1^{\circ}$ de la CPR dispone: "El ejercicio de la soberanía reconoce único como limitación el respeto a los derechos esenciales que emanan de la naturaleza humana".

${ }^{4}$ Cfr. Nogueira, H. "Consideraciones sobre el Derecho Fundamental a la presunción de inocencia", Revista Ius et Praxis, Talca, Vol. 11, No 1, 2005, p. 222.

${ }^{5}$ Cfr. Jara, J: Op. cit., p. 41.

${ }^{6}$ Con todo, existe aún discusión sobre la jerarquía de las normas contenidas en los tratados internacionales sobre Derechos Fundamentales. Ver en este sentido, Pfeffer, E. "Los tratados internacionales sobre Derechos Humanos y su ubicación en el orden normativo interno", Revista Ius et Praxis, Talca, Vol. 9, N ${ }^{\circ}$ 1, 2003, pp. 467-484. Ver también, Nogueira, H. "La reforma constitucional del 2005 y control de constitucionalidad de los tratados internacionales”, Estudios constitucionales: Revista del Centro de Estudios Constitucionales, Talca, Año 5, No 1, 2007, pp. 59-88.

${ }^{7}$ Cfr. Nogueira, H: Op. cit., p. 226. 


\section{Presunción de inocencia y prueba}

En el contexto de la prueba en el proceso penal, el derecho a la presunción de inocencia adquiere una doble manifestación, como regla probatoria y como regla de juicio.

Es así como en la primera de estas -regla probatoria- supone la necesaria existencia de actividad probatoria de cargo practicada con todas las garantías ${ }^{8}$. De otro lado, en su función de regla de juicio, asume un papel relevante al momento de la valoración de la prueba exigiendo la existencia de los criterios necesarios para que el juez logre la decisión sobre el caso concreto, así como también, el resultado de la misma en los casos en que la prueba de cargo sea insuficiente?

\subsection{Presunción de inocencia y valoración de la prueba}

La doctrina procesal está de acuerdo en que la influencia del derecho a la presunción de inocencia, en el proceso penal, hace que la actividad probatoria sea el eje de giro de su contenido esencial ${ }^{10}$. De este modo, el derecho a la presunción de inocencia no solo sirve para asignar el onus probandi, sino que además sirve como criterio de decisión del juez al exigir la absolución del acusado cuando la prueba sea insuficiente. Ahora bien, para poder determinar cuando la prueba es insuficiente, o a contrario sensu, cuando el juez puede condenar -debido a que dispone de elementos de juicio que permitan acreditar la comisión del hecho punible y la participación del acusado en el mismo- el legislador debe determinar el umbral de suficiencia de la prueba requerida mediante un estándar de prueba -elemento que se desarrollará más adelante en este trabajo-. Luego, el derecho a la presunción de inocencia requiere que se fije el quantum de la prueba ${ }^{11}$, esto es, que la culpabilidad del acusado, por el hecho delictual que se le acusa, ha de quedar probada, en los términos del art. 340 inc. $1^{\circ}$ del CPP, más allá de toda duda razonable ${ }^{12}$.

Ahora bien, el art. 297 del CPP ${ }^{13}$ establece el sistema de valoración de la prueba en nuestro proceso penal. Se consagra un sistema de libre valoración, el cual a diferencia del sistema de prueba legal tasada en el que el legislador establecía de antemano el valor que

${ }^{8}$ Para esto ver: Horvitz, M. y López, J. Derecho procesal penal chileno, Tomo I y II, Editorial Jurídica de Chile, Santiago, año 2002-2004.

${ }^{9}$ Cfr. Fernández, M. Prueba y presunción de inocencia, Editorial Iustel, Madrid, 2005, pp. 157-158.

${ }^{10}$ Cfr. Romero, E. La presunción de inocencia: Estudio de algunas consecuencias de la Constitucionalización de este Derecho Fundamental, Editorial Aranzadi, Madrid, 1981, p. 60. Ver también, Luzón, J. La presunción de inocencia ante la casación, Editorial Colex, Madrid, 1991, p. 13., Pedrajas, A. Op. cit., p. 227.

${ }^{11}$ Cfr. Igartua, J. "Motivación de las sentencias, presunción de inocencia 'In dubio pro reo'”, Anuario de Derechos Humanos, Universidad Complutense de Madrid, N², Madrid, 2001, p. 460.

${ }^{12}$ Cfr. Tadros, V. "Rethinking the presumption of innocence", Criminal law and philosophy, Vol. 1, issue 3, Springer Science + Business Media B.V, Netherlands, 2007, p. 197.

${ }^{13} \mathrm{El}$ art. 297 del CPP en su inciso $1^{\circ}$ dispone: "Valoración de la prueba. Los tribunales apreciarán la prueba con libertad, pero no podrán contradecir los principios de la lógica, las máximas de la experiencia y los conocimientos científicamente afianzados". 
correspondía a cada prueba ${ }^{14}$, permite a los jueces la apreciación libre de esta, no pudiendo contradecir los principios de la lógica, las máximas de la experiencia y los conocimientos científicamente afianzados. Lo anterior implica que las pruebas valen según el grado de convicción que genera en el ente juzgador ${ }^{15}$. Ahora bien, esta convicción no debe habilitar espacios de arbitrariedad, toda vez que esta valoración lleva aparejada la condición de justificación racional de la sentencia ${ }^{16}$ tal y como lo ordena el art. 342 letra c del $\mathrm{CPP}^{17}$.

Luego, la presunción de inocencia al exigir la fijación del quantum probatorio para formar la convicción necesaria del ente juzgador, obliga a este a que su decisión sea motivada, por lo que le exige exteriorizar el razonamiento que lo llevó a establecer como probados los enunciados de los hechos vertidos en juicio, así como también los medios de prueba existentes en el proceso que utilizó para la posterior aplicación de las normas decisoria litis $^{18}$.

Ahora bien, en su faceta de regla de juicio implica la necesaria absolución cuando esta prueba de cargo es insuficiente, o sea, no ha sido posible llegar a la convicción que exige el art. 340 de nuestro CPP. Así las cosas, nos encontramos ante dos fases bien diferenciadas en el estadio probatorio. La primera fase es aquella en la que el juez determina la existencia de actividad probatoria de cargo. Una vez que verifica esta situación es cuando comienza la segunda fase, la de valoración de la prueba, cuyo fin es determinar si la prueba de cargo es suficiente para superar el estándar de prueba requerido por la ley, ergo suficiente o no para condenar ${ }^{19}$.

Es en esta fase de valoración de la prueba en el que el peligro de la arbitrariedad se presenta con mayor fuerza, ya que la determinación de la suficiencia de la prueba de cargo es uno de los momentos de la valoración en las que simples sospechas o conjeturas pueden presentarse como elementos de prueba convincentes y por lo tanto suficientes. Luego, la única forma eficaz de evitar tal peligro reside en permitir el examen exhaustivo de toda la actividad de valoración, desde la selección de los medios de prueba en los que se fundamente la sentencia hasta el razonamiento empleado por el juez para condenar ${ }^{20}$.

Y esto debido a que el momento de la valoración de la prueba es el más importante a todos los efectos, a causa de que en este estadio procesal el juzgador puede dictar sentencia absolutoria o condenatoria, ergo, la inocencia o culpabilidad del acusado depende de esta actividad. Por tanto la condena no puede ser la expresión de una decisión

${ }^{14}$ Cfr. Vásquez J. Presunción de inocencia del imputado e "intima convicción" del tribunal (estudios sobre la utilización del imputado como fuente de prueba en el proceso penal español), Editorial Bosch, Madrid, 1984, p. 450.

${ }^{15}$ Cfr. Igartua, J. Op. cit., p. 462.

16 Ibid., p. 465.

${ }^{17}$ El art. 342 letra c del CPP expresa que la sentencia debe contener: "La exposición clara, lógica y completa de cada uno de los hechos y circunstancias que se dieren por probados, fueren ellos favorables o desfavorables al acusado, y de la valoración de los medios de prueba que fundamentaren dichas conclusiones de acuerdo con lo dispuesto en el artículo 297".

${ }^{18}$ Cfr. Colombo, J. "Garantías constitucionales del debido proceso penal. Presunción de inocencia”. Anuario de derecho constitucional latinoamericano 2007, Edición UNAM, México D.F., p. 349.

${ }^{19}$ Cfr. Fernández, Me.s: Op. cit., p. 244.

${ }^{20}$ Cfr. Ibid., pp. $250-251$. 
arbitraria, ilógica o no racional del juzgador ${ }^{21}$. De lo contrario, se estaría vulnerando el derecho a la presunción de inocencia.

Entonces, y siguiendo a Nogueira:

“...se vulnera la presunción de inocencia cuando se condena a una persona con meras sospechas, sin pruebas o prescindiendo de ellas; cuando se presume la culpabilidad del imputado, imponiéndole la carga del onus probandi, de su inocencia; (...); como también cuando se condena en virtud de pruebas irregularmente obtenidas o hechas valer, violando derechos fundamentales o sin las garantías constitucional y legalmente debidas o cuando de hechos no probados se extraigan consecuencias jurídicas sancionatorias que afecten los derechos fundamentales..."22.

De esta forma en el derecho a la presunción de inocencia "confluye una idea común, donde se pretende evitar la condena irrazonable o arbitraria" 23 .

\subsection{Presunción de inocencia y estándar de prueba}

La consagración de la presunción de inocencia como derecho fundamental proscribe la condena en la duda, porque, establece el hecho inicialmente cierto de que todo hombre es inocente. De la postura inicial sobre la inocencia el juez puede llegar a la contraria, pero solo dentro del proceso, merced de una actividad probatoria y tras una valoración o apreciación libre de la prueba. Luego, para condenar, hace falta la certeza de la culpabilidad obtenida de la valoración de la prueba. Solo desde el convencimiento firme se puede condenar, no desde la duda ni menos desde la arbitrariedad ${ }^{24}$.

Por lo que si llega a la certeza, debe ser solo dentro del proceso, o sea, valiéndose de las herramientas procesales que la ley prevé, en tal caso, la única forma de llegar a la certeza en el proceso penal -de acuerdo con dichas herramientas legales- es superando el estándar de prueba establecido en la ley.

Así las cosas, el estándar de prueba debe formularse de tal forma que permita llegar a una decisión racional sobre la acreditación de los enunciados sobre los hechos vertidos en el juicio, es decir, a una decisión susceptible de justificación.

Es dentro del proceso, como se ha mencionado anteriormente, que la presunción de inocencia alcanza plena virtualidad y sentido ${ }^{25}$, de tal forma si la presunción de inocencia

${ }^{21}$ Cfr. Belda, E. "La presunción de inocencia", Parlamento y Constitución, anuario $\mathrm{N}^{\circ}$ 5, Ciudad Real, 2001, pp. 192-193.

${ }^{22}$ Nogueira, H. “Consideraciones sobre el...”, cit., p. 237.

${ }^{23}$ Gozaíni, O. "La presunción de inocencia del proceso penal al proceso civil”, Revista Latinoamericana de Derecho, No 6, UNAM, México D.F., p. 175.

${ }^{24}$ Cfr. Tomas y Valiente, F. “ «In dubio pro reo», libre apreciación de la prueba y presunción de inocencia”, Revista española de Derecho Constitucional, año 7, N²0, mayo/agosto, Madrid, 1987, p. 25.

25 Cfr. Pedrajas, A. "Derecho a la presunción de inocencia y proceso de trabajo", Derecho Privado y Constitución, No 4, Madrid, 1994, p. 228. 
demanda la interdicción de la arbitrariedad en el proceso, esta en su calidad de derecho fundamental y en virtud del principio de supremacía constitucional, viene a inspirar e informar al proceso penal en tal sentido, eliminando así cualquier resquicio en el cual pueda albergarse la arbitrariedad.

Luego, si en virtud de lo prescrito en los art. $5^{\circ}$ inc. $2^{\circ}$ y $6^{\circ}$ inc. $1^{\circ}$ y $2^{\circ}$ de la CPR se obliga a todos los órganos del Estado los cuales deben promover el derecho a la presunción de inocencia, esta interdicción de la arbitrariedad en el proceso se extiende también a la actividad de los jueces, toda vez que estos son órganos del Estado y como tales se encuentran vinculados a los preceptos constitucionales mencionados, debiendo entonces en la fase de valoración de la prueba actuar con objetividad, para así alcanzar la convicción racional sobre la comisión del hecho punible y la participación que le asiste al acusado, a contrario sensu, su convicción no puede ser subjetiva o arbitraria.

Es así como en el proceso penal el derecho a la presunción de inocencia impone un mandato de prohibición de la arbitrariedad. Luego, todas las herramientas procesales que actúan en el proceso deben necesariamente apuntar a este ideal de racionalidad y objetividad. Es en este punto donde adquiere importancia fundamental el estándar de prueba, instrumento del proceso cuya función de umbral permite al juez alcanzar o no la convicción según si las pruebas aportadas en el juicio son suficientes para destruir la presunción de inocencia, funcionando entonces como garantía de protección de este derecho.

De tal forma, en esta crítica etapa procesal, en la cual se decide si se absuelve o se condena al acusado, se debe poner la mayor atención en mantener el mandato de racionalidad y objetividad que la presunción de inocencia impone.

Cabe preguntarse entonces, si nuestro estándar de prueba cumple el mandato de objetividad y racionalidad que emana del derecho a la presunción de inocencia, y por tanto si cumple o no el rol de garantía de éste en el proceso penal.

\section{Estándar de PRUEba EN EL PROCESO PENAL CHILENO}

\subsection{Dentro de un contexto de incertidumbre}

Desde un punto de vista epistemológico, el objeto del proceso es la verdad ${ }^{26}$ y "ello no puede ser de otra manera, puesto que ese objetivo es estructuralmente necesario para que funcione el propio derecho como mecanismo de motivación de la conducta" 27 . Ahora, si bien en el contexto procesal no se puede alcanzar una verdad absoluta debido a

${ }^{26}$ En este sentido ver: Ferrer, J. Prueba y verdad en el derecho, Editorial Marcial Pons, Madrid, 2002, Ferrer, Jordi: Valoración racional de la prueba, editorial Marcial Pons, Madrid, 2007,Taruffo, M. La prueba de los hechos, Editorial Trotta, Madrid, 2002, Taruffo, M. Simplemente la verdad, Editorial Marcial Pons, Madrid, 2010.

${ }^{27}$ Ferrer, J. "La prueba es libertad, pero no tanto. Una teoría de la prueba cuasi-Benthamiana”, en Accatino, D. (coordinadora), Formación y valoración de la prueba en el proceso penal, LegalPublishing, Santiago, 2010, p. 13. 
límites legales o prácticos, esto no impide que el proceso sea un contexto de búsqueda y aproximación a la verdad que tiene reglas y límites propios, como sucede en el resto de contextos prácticos donde se averiguan hechos ${ }^{28}$, de forma tal que, podemos decir que en el proceso penal, el juicio oral es una herramienta epistémica, un medio para llegar a una verdad a partir de lo que usualmente sería una confusa presentación de hechos e hipótesis ${ }^{29}$.

Sin embargo, el hecho que se busca probar durante el juicio -el cual constituye el tipo penal por el que se acusa y cuya autoría le cabría al acusado- es un hecho único e irrepetible, ocurrido en un contexto espacio/temporal distinto al del juicio, el cual no ha sido presenciado por el juez directamente y que a priori este no sabe si ha ocurrido o no en el mundo real. Por tanto, cabe precisar que la decisión final sobre los hechos del caso es una decisión adoptada en condiciones de incerteza aunque se encuentra dirigida a la eliminación de dicha incerteza. Esta incertidumbre, es decir la duda entre verdad y falsedad, caracteriza a los hechos que se proponen al comienzo del proceso en la acusación realizada por el Fiscal, o lo que es lo mismo, estos hechos son pretensiones de verdad que pueden ser verdaderas o falsas ${ }^{30}$.

De esta nota de incertidumbre, podemos derivar que en lo relativo a la toma de decisiones en el ámbito de la prueba jurídica, la confirmación del valor de verdad que podemos atribuir a las conclusiones judiciales se relativiza. Esto no quiere decir que no se pueda atribuir valor de verdad a las proposiciones que se declaran probadas en un proceso, sino más bien, que el conjunto de pruebas de que se disponga en el mismo permite atribuir un determinado grado de probabilidad de que esa proposición sea verdadera $^{31}$, siendo la etapa de valoración de la prueba el estadio procesal en donde el Tribunal determina qué hipótesis de las diversas en conflicto en el proceso tiene un más alto grado de probabilidad ${ }^{32}$.

Ahora bien, en el contexto del juicio oral, el Tribunal es ajeno a los hechos que se buscan probar, de tal forma las pruebas de estos no son el resultado directo de la observación de los juzgadores, sino de una inferencia que se realiza a partir de otros enunciados probatorios $^{33}$, o lo que es lo mismo, el conocimiento del juez es un conocimiento inductivo, el cual no es capaz de dotar a sus conclusiones de certeza demostrativa ${ }^{34}$.

Luego, "debido a que la verdad de una hipótesis no puede ser demostrada con certeza, sino solo corroborada en menor o mayor medida, se necesita que el derecho

${ }^{28}$ Cfr. Taruffo, M. “Algunos comentarios sobre la valoración de la prueba”, Discusiones: Prueba y conocimiento, $\mathrm{N}^{\circ} 3$, Madrid, 2003, p. 87.

${ }^{29}$ Cfr. Laudan, L. Truth, Error and Criminal Law, an essay in legal epistemology, Cambridge University Press, Reino Unido, 2006, p. 2.

${ }^{30}$ Cfr. Taruffo, M. Simplemente la verdad, Editorial Marcial Pons, Madrid, 2010, p. 221.

${ }^{31}$ Ferrer, J. Valoración racional de la prueba, Editorial Marcial Pons, Madrid, 2007, p. 26.

${ }^{32}$ Cfr. Ferrer, J. "La prueba es libertad, pero...", cit., p. 16.

33 Cfr. Gascón, M. Los hechos en el Derecho, Editorial Marcial Pons, Madrid, 1999, p. 98.

${ }^{34}$ Cfr. Accatino, D. "El modelo legal de justificación de los enunciados probatorios en las sentencias penales y su control a través del recurso de nulidad", en Accatino, D. (coordinadora) Formación y valoración de la prueba en el proceso penal, LegalPublishing, Santiago, 2010, p. 125. 
defina el umbral de corroboración suficiente para que esté justificado declarar probado un enunciado fáctico" 35 . O en otras palabras, se debe "determinar el grado de probabilidad suficiente para dar por probada la hipótesis" 36 . Dicho grado es definido mediante el estándar de prueba.

\subsection{Estándar de prueba en el proceso penal}

En el contexto de un conocimiento relativo o imperfecto de los hechos que tiene lugar en la prueba judicial ${ }^{37}$ y dentro de un proceso que tiene como objetivo averiguar la verdad acerca de la comisión de un delito, los estándares de prueba juegan un rol fundamental en la problemática de cómo puede estructurarse un juicio para elevar al máximo la probabilidad de que el resultado sea un fallo verdadero ${ }^{38}$, es decir, que su contenido se corresponda con la realidad, constituyendo uno de los "engranajes claves del proceso judicial que posibilitan a los jueces la elección justificada de un cierto curso de acción"39.

En tal sentido, podemos definir al estándar de prueba como aquella herramienta legal que contiene los criterios que indican cuando se ha conseguido la prueba de un becho ${ }^{40}$. Luego, el estándar permite entonces indicar cuándo está justificado aceptar como verdadera la hipótesis que describe tales hechos. Esto implica en primer lugar decidir qué grado de probabilidad o certeza se requiere para aceptar una hipótesis como verdadera, y en segundo lugar, implica formular objetivamente el estándar de prueba, es decir, formular los criterios objetivos que indican cuándo se alcanza ese grado de probabilidad o certeza exigida $^{41}$.

Como se expresó previamente, el sistema de valoración de la prueba en el ordenamiento jurídico chileno de acuerdo con el art. 297 inc. $1^{\circ}$ del CPP, es el de libre valoración de la prueba. Ahora bien, esta libertad no puede ser entendida como la ausencia de límites sobre los jueces en su proceso de toma de decisión sin sujeción a regla alguna $^{42}$. Sostener tal posición traería como consecuencia que el juez pudiera llegar a la convicción por un sistema intelectivo particular y subjetivo, pasando a interpretarse la libre convicción como una convicción íntima del juzgador, y por tanto intransferible e

35 Accatino, D. Op. cit., p. 133.

${ }^{36}$ Ferrer, J. Valoración racional de..., cit., p. 139.

${ }^{37}$ Cfr. Gascón, M. "Sobre la posibilidad de formular estándares de prueba objetivos”, DOXA: Cuadernos de filosofía del Derecho, No 28, Madrid, 2005, p. 128.

${ }^{38}$ Cfr. Laudan, L. "Porque un estándar de prueba subjetivo y ambiguo no es un estándar", DOXA: Cuadernos de filosofía del Derecho, No 28, Madrid, 2005, p. 96.

39 Coloma, R. "Estándares de prueba y juicios por violaciones a los Derechos Humanos", Revista de Derecho Universidad Austral de Chile, Vol. XXII, N²,2009, Valdivia, p. 207.

${ }^{40}$ Cfr. Gascón, M. "Sobre la posibilidad de formular...", cit., p. 129.

${ }^{41}$ Cfr. Ibid., p. 129.

${ }^{42}$ Cfr. Coloma, R. "Panorama general de la prueba en el juicio oral chileno", en Coloma, R. (editor), La prueba en el nuevo proceso penal, Lexis Nexis, Santiago, 2003, p. 24. 
incomunicable sobre los hechos que juzga, abriendo la puerta a un sistema subjetivista sobre la valoración de la prueba de pura arbitrariedad judicial ${ }^{43}$.

Es por esto que el artículo del CPP ya citado establece ciertos límites sobre los jueces, en el sentido de que no pueden llegar a cualquier conclusión a partir de la información que ha sido incorporada al juicio, a saber, los principios de la lógica, las máximas de la experiencia y los conocimientos científicamente afianzados ${ }^{44}$.

Es así como "se deja atrás la imagen subjetivista y puramente potestativa del principio de valoración de la prueba reconociéndose que el descarte de las reglas de tasación legal no implica la exclusión de toda regla, sino más bien la sujeción solo a los criterios de racionalidad de la epistemología general" ${ }^{45}$. Por tanto, a diferencia de lo que ocurre en el modelo tasado, las pruebas pasan a ser condiciones necesarias mas no suficientes por sí solas para justificar la convicción, la cual solo en este sentido puede ser reputada libre. Sostener lo contrario, es decir, la libre convicción sin sujeción a regla racional alguna, equivale a permitir un juicio autoritario por parte del juez en el sentido de la formación del juicio de culpabilidad con independencia de las pruebas rendidas en juicio ${ }^{46}$.

Así las cosas, es en el contexto de un sistema de valoración racional de la actividad probatoria en donde el estándar de prueba se inserta y adquiere sentido, siendo un criterio conforme al cual deberá el juez formular su valoración racional sobre los hechos de la causa y también sobre el cual ha de reconstruirse la justificación de la decisión probatoria ${ }^{47}$.

\subsection{Funciones del estándar de prueba}

Si bien en el proceso la verdad es un valor estructural y fin último a alcanzar mediante la actividad probatoria, esta finalidad se traduce en la búsqueda de la reducción del error. En tal sentido, en el proceso penal se debe apuntar a descubrir la verdad sobre la comisión de un delito para así evitar veredictos falsos. Ahora bien, como en toda actividad humana, se debe reconocer que los errores van a estar presentes, y en el proceso penal estos errores, de naturaleza epistémica, consisten en absoluciones falsas y en condenas falsas ${ }^{48}$.

Como se expresó previamente, los criterios de racionalidad con los que debe operar la libre valoración de la prueba no pueden por sí solos determinar si el apoyo inductivo que aportan las pruebas a una hipótesis es suficiente para declararla probada en el proceso. Para adoptar esta decisión -sobre cuánta prueba es suficiente para declarar por probada una hipótesis- el derecho debe definir el nivel de suficiencia de los elementos de juicio por medio del estándar de prueba. Luego, el nivel de suficiencia apropiado determinado en el estándar de prueba permite hacerse cargo de resolver la problemática

\footnotetext{
${ }^{43}$ Cfr. Gascón, M. Los hechos en el Derecho..., cit., p. 159.

${ }^{44}$ Cfr. Coloma, R. "Panorama general de la prueba..., cit., p. 24.

45 Accatino, D. Op. cit., p. 119.

${ }^{46}$ Cfr. Ferrajoli, L. Derecho y razón, Editorial Trotta, Madrid, 1995, p. 611.

${ }^{47}$ Cfr. Gascón, M. "Sobre la posibilidad de formular...", cit., p. 129.

${ }^{48}$ Cfr. Laudan, L. Truth, Error and Criminal..., cit., p. 1.
} 
de la distribución de estos errores epistémicos en los que inevitablemente se incurrirán dentro del proceso ${ }^{49}$.

Así, el estándar de prueba es un mecanismo que permite distribuir los errores judiciales en la declaración de hechos probados. Un falso positivo, es una decisión en que se declara probada la hipótesis siendo esta falsa. Un falso negativo, por su parte, es una decisión en que se declara no probada la hipótesis, siendo esta verdadera. Luego, estas decisiones pueden ser válidas procesalmente hablando pero fallan en el objetivo último del proceso, esto es, la averiguación de la verdad sobre la comisión del delito ${ }^{50}$.

El significado detrás de la noción de distribución del error corresponde a qué errores estamos dispuestos como sociedad a aceptar. Así en el proceso penal, si un falso positivo - condena falsa- tiene un impacto potencial más grave que un falso negativo -absolución falsa-, el riesgo debiera ser distribuido diferenciadamente ${ }^{51}$. Luego, en la medida en que se hace más alto o exigente el estándar de prueba, van a aumentar los falsos negativos y disminuyen los falsos positivos ${ }^{52}$.

Y entonces, ¿de qué forma se distribuye el error en el proceso penal?

La distribución del error supone una determinada elección político-valorativa sobre la intensidad con que deben ser garantizados los derechos o intereses afectados por cada uno de los errores posibles, es decir, dependiendo de la importancia que se conceda a los derechos o intereses afectados por cada tipo de error, el estándar de prueba será más o menos tolerante con ese tipo de error ${ }^{53}$.

En el proceso penal, el costo de una condena errónea es considerado significativamente más grave que el de una absolución errónea y por esta razón se impondría un estándar de prueba particularmente exigente ${ }^{54}$, haciendo altamente difícil condenar a alguien, salvo "al más obvio culpable" 55 .

Esta alta exigencia del estándar de prueba es concordante con el objetivo de averiguación de la verdad del proceso penal, pues solo se busca condenar a quien es verdaderamente culpable de la comisión del delito. Cabe decir también que cuanto más exigente sea el estándar para tener por probado un hecho, más racional será la decisión que declara probado ese hecho, pues un estándar probatorio muy exigente minimiza la posibilidad de error y por lo tanto maximiza la posibilidad de acierto $^{56}$.

Sin embargo, "el cumplimiento del estándar no garantiza la no comisión de errores de ningún tipo. Debido a que el estándar es muy exigente, es previsible que se cometan más errores del tipo falso negativo -absoluciones falsas- que del tipo falso positivo -condenas falsas-“"

\footnotetext{
${ }^{49}$ Cfr. Accatino, D. Op. cit., p. 133.

${ }^{50}$ Cfr. Ferrer, J. Valoración racional de..., cit., p. 143.

${ }^{51}$ Cfr. Accatino, D. Op. cit., p. 134.

52 Cfr. Ferrer, J. Valoración racional de..., cit., p. 143.

53 Cfr. Gascón, M. "Sobre la posibilidad de formular..., cit., pp. 130-131.

${ }^{54}$ Cfr. Accatino, D. Op. cit., p. 134.

${ }^{55}$ Laudan, L. Truth, Error and... cit., p. 29.

${ }^{56}$ Cfr. Gascón, M. "Sobre la posibilidad de formular...", cit., p. 130.

${ }^{57}$ Ferrer, J. Valoración racional de..., cit., p. 148.
} 
Luego, en el proceso penal "no se está particularmente interesado de forma general en la reducción o eliminación de errores, sino que tiende a distribuir los errores de forma tal que favorezcan sistemáticamente la posición del imputado" 58 , y así, "conforme disminuye la posibilidad de errar al declarar probado un hecho, aumenta la posibilidad de errar al darlo por no probado" 59 .

En cumplimiento de la función de distribución del riesgo de error, los estándares de prueba permiten operar válidamente en contextos de incertidumbre, por cuanto las decisiones que se adopten en el curso del proceso y que pudieren estar afectadas de errores epistémicos, de todas formas se podrán calificar como decisiones conforme a derecho. De esta forma, el estándar de prueba se hace cargo de la falibilidad del conocimiento que le asiste a la decisión judicial. Luego, los estándares autorizan la aplicación de una pena, incluso habiendo riesgos de errar en el proceso de reconstrucción de la realidad que supone el juicio. Para ello bastará que se superen las exigencias previstas en el respectivo estándar de prueba ${ }^{60}$.

Ahora bien, el derecho a la presunción de inocencia exige una decisión motivada del juez, en la que se dé cuenta que las pruebas aportadas han sido tomadas en consideración y valoradas racionalmente ${ }^{61}$. Solo mediante esta justificación es posible determinar si se ha destruido la presunción de inocencia que le asiste al acusado. Luego, esta explicitación de los criterios seguidos por el juzgador y la argumentación de las razones por las que este ha considerado que un determinado hecho estaba probado o no probado, permite evitar que las decisiones sean tomadas según el arbitrio subjetivo del juez y por tanto, habilita un control intersubjetivo de la fundamentación de la decisión ${ }^{62}$. Ahora bien, la justificación de la decisión judicial será incompleta si no se justifica la concurrencia de los elementos que componen el estándar, toda vez que solo superando este último es posible llegar a la convicción sobre la ocurrencia del delito que se discute. Así las cosas, y como se expresó previamente, el estándar de prueba cumple, aparte de su función de distribución de error, una función justificadora conforme a la cual ha de reconstruirse la justificación de la decisión probatoria ${ }^{63}$.

En resumen, son tres las funciones que le asisten al estándar de prueba. En primer lugar, como herramienta procesal que permite establecer el nivel de suficiencia necesaria para que el juez pueda tener por acreditado la ocurrencia de un hecho, es decir, establece el quantum probatorio necesario para que el juzgador pueda declarar por probada una hipótesis y en tal sentido es un instrumento procesal orientado a la averiguación de la verdad. En segundo lugar y relacionado con lo primero, el estándar probatorio

58 Taruffo, M. "Tres observaciones sobre "porque un estándar de prueba subjetivo y ambiguo no es un estándar” de Larry Laudan”, DOXA: Cuadernos de Filosofía del Derecho, No 28, Madrid, 2005, p. 117.

59 Gascón, M. "Sobre la posibilidad de formular...”, cit., p. 130.

${ }^{60}$ Cfr. Coloma, R. "Estándares de prueba y juicios por...”, cit., pp. 211-212.

${ }^{61}$ Cfr. Accatino, D. "La fundamentación de la declaración de hechos probados en el nuevo proceso penal. Un diagnóstico", en, Revista de Derecho Universidad Austral de Chile, Vol. XIX, No 2, Valdivia, 2006, p. 10.

${ }^{62}$ Cfr. Taruffo, M. “Tres observaciones sobre...", cit., p. 121.

${ }^{63}$ Cfr. Gascón, M. "Sobre la posibilidad de formular...”, cit., p. 138. 
tiene una función de distribución de los errores epistémicos, la que en armonía con el derecho a la presunción de inocencia tolera las absoluciones falsas en pos de condenar al "verdaderamente" culpable de la comisión de un delito, para lo cual este estándar debe ser formulado en términos objetivos y exigentes. Sin perjuicio de lo anterior, en atención a esta segunda función, de forma general pareciera ser que el estándar de prueba en materia penal al no buscar la eliminación o reducción de los errores epistémicos y si la distribución de los mismos, no cumpliría con el objetivo de búsqueda de la verdad entrando en contradicción la primera y la segunda función. Sin embargo, esto a mi parecer no es así y merece la siguiente precisión. Si bien un estándar de prueba formulado en términos exigentes como en el proceso penal aumenta la probabilidad de falsos negativos y en ese sentido pareciera ser que entra en conflicto con el objetivo de averiguación de la verdad, no es menos cierto que, en virtud de esta alta exigencia, la declaración de un hecho como probado tiene una alta probabilidad de ocurrencia en el mundo exterior. Y en tal sentido, un estándar de prueba exigente sí se correspondería con el objetivo de búsqueda de la verdad en el proceso, si nos referimos a la verdad de la acusación. Por último, esta herramienta procesal tiene una función justificadora de la decisión probatoria, la cual obliga al juez a explicitar en la motivación de la sentencia si se cumplen o no los presupuestos establecidos por el estándar probatorio para sobrepasar el umbral de suficiencia necesaria que permite declarar un hecho como probado.

\subsection{El caso chileno: Más allá de toda duda razonable}

En las tradiciones jurídicas del derecho romano-germánico y del common law se han utilizado dos estándares probatorios en el proceso penal, a saber; la "íntima convicción” y el "más allá de toda duda razonable" ${ }^{4}$. Siendo este último, el consagrado en nuestro CPP en el art. 340 inc. $1^{\text {o65 }}$. De acuerdo con la historia de la tramitación del CPP:

"La Comisión Mixta tuvo presente que el estándar de convicción más allá de toda duda razonable es propio del derecho anglosajón, y no del europeo continental, por lo que resulta una novedad también para el ordenamiento jurídico chileno. Sin embargo, es un concepto útil, toda vez que está suficientemente decantado y elimina las discusiones relativas al grado de convicción que se requiere, dejando en evidencia que no se trata de una convicción absoluta, sino de aquella que excluya las dudas más importantes" 66 .

${ }^{64}$ Cfr. Ferrer, J. Valoración racional de..., cit., p. 144.

${ }^{65}$ Bajo el epígrafe "convicción del tribunal" el art. 340 en su primer inciso dispone: "Nadie podrá ser condenado por delito sino cuando el tribunal que lo juzgare adquiriere, más allá de toda duda razonable, la convicción de que realmente se hubiere cometido el hecho punible objeto de la acusación y que en él hubiere correspondido al acusado una participación culpable y penada por la ley”. Cursivas son mías.

66 "Informe de la Comisión Mixta”, en Historia de la ley 19.696, p. 2005. Cursivas son mías. 
Si bien el párrafo antes citado expone de manera correcta que la convicción no puede ser absoluta, falla en estimar que el significado de este estándar probatorio es un concepto "suficientemente decantado y que elimina las discusiones relativas al grado de convicción que se requiere”. Como se demostrará en las páginas siguientes de este trabajo, el estándar "más allá de toda duda razonable" adolece de una vaguedad extrema que le impide ser la herramienta de control intersubjetivo de la decisión judicial necesaria para resguardar el derecho a la presunción de inocencia, transformándose en "una noción de prueba gravemente inadecuada, deliberadamente confusa, completamente subjetiva y abierta a tantas interpretaciones como jueces existan"67.

\subsection{Razonabilidad de la duda razonable}

¿Qué significa más allá de toda duda razonable? Esta pregunta ha sido motivo de un intenso debate en la jurisprudencia y doctrina anglosajona por más de un siglo. Los tribunales de justicia norteamericanos han dado diversas interpretaciones a lo que debe entenderse por una prueba más allá de una duda razonable. Así se ha entendido que esta corresponde a una certeza moral -en contraposición a una certeza matemática-, otra interpretación sugiere que es la seguridad o creencia apropiada en las decisiones importantes de la vida, también se ha entendido como la clase de dudas que haría a una persona prudente titubear de actuar, igualmente se ha interpretado como una convicción perdurable de culpabilidad, e incluso se ha expresado que la duda razonable es aquella duda que amerita el otorgamiento de una razón 68 .

Ahora bien, la coexistencia de distintas definiciones de "más allá de toda duda razonable” en sí misma no es necesariamente algo malo. Lo problemático es que todas aquellas definiciones fallan en desarrollar una idea subyacente. Tener una convicción perdurable de culpabilidad no es lo mismo que tener la seguridad para tomar una decisión importante en la vida, ni tampoco tener una duda por la cual amerite darse una razón. A lo que nos enfrentamos aquí no son distintas formas de desarrollar un mismo concepto, si no que son concepciones absolutamente distintas sobre la base y nivel de prueba necesaria para condenar a alguien ${ }^{69}$, ergo, no existe un concepto de duda razonable.

Esta situación ha llevado a las Cortes norteamericanas a insistir que no se debe definir lo que es una duda razonable, expresando que esta es "autoevidente" y se "define a sí misma”, por lo que no necesita mayor comentario ${ }^{70}$. Así las cosas, sostener que el concepto de "más allá de toda duda razonable" se encuentra "suficientemente decantado”, es una aseveración que, a lo menos, se encuentra bastante alejada de la realidad.

Sin perjuicio de lo anterior, el rasgo en común de las diversas nociones de "más allá de toda duda razonable" es que se definen en términos subjetivos, es decir, apelan al

\footnotetext{
${ }^{67}$ Laudan, L. Truth, Error and... cit., p. 30.

${ }^{68}$ Cfr. Laudan, L. Truth, error and... cit., p. 33 y ss.

${ }^{69}$ Cfr. Ibid., p. 47.

${ }^{70}$ Cfr. Ibid., p. 49.
} 
estado mental que debe tener el juzgador -convicción o duda-al momento de condenar o absolver al acusado ${ }^{71}$.

\subsection{En presencia de un estándar de prueba subjetivo}

Los problemas con el estándar consagrado en nuestro art. 340 inc. $1^{\circ}$ del CPP, comienzan con la extrema vaguedad en su formulación. La falta de un criterio de razonabilidad de la duda se traduce en una imprecisión del estándar, la cual no permite establecer con claridad cuál es el grado de duda tolerable ${ }^{72}$.

El problema de la vaguedad en la formulación de este estándar de prueba se ve agravado por el predominio, en la doctrina y en la práctica procesal penal, de una interpretación subjetivista del mismo -favorecida por la expresión "convicción” utilizada en el art. 340 CPP- que lo entiende referido a un estado mental del juzgador, consistente en la creencia en la verdad del hecho que se trata $\operatorname{probar}^{73}$.

Esta interpretación como remisión al estado mental del juzgador adolece de los siguientes defectos. Primero, dicha noción parece apelar a la idea de certeza y como se ha señalado anteriormente ningún razonamiento inductivo permite dotar de certeza a sus conclusiones, sostener lo contrario sería aceptar una concepción irracional de la prueba llevándonos a un "modelo de actividad probatoria como convencimiento del juez"74. Segundo, esta concepción establece que la creencia del juzgador en el hecho, es la prueba del hecho, trayendo la indeseable consecuencia de constituir al juez en un sujeto infalible respecto de la determinación de los hechos, ya que los hechos son lo que el juez dice que $\operatorname{son}^{75}$. Ahora bien, esta noción de infalibilidad es incompatible con un proceso cuyo fin es el de la averiguación de la verdad. Por último, estando ante un estándar que apela a las creencias del sujeto que decide, este tiene un carácter enteramente subjetivo que hace incontrolable su aplicación, y en tal sentido podemos decir que no nos encontramos ante un estándar de prueba propiamente $\operatorname{tal}^{76}$.

Este modelo subjetivo de estándar, convierte la existencia de una prueba de culpabilidad en una actividad parasitaria a la existencia previa de una convicción firme de culpabilidad. Es decir, solo se tendrá una prueba cuando el juzgador esté convencido de la existencia de esta. Fuera del derecho, la confianza racional en una conjetura sigue a su prueba, nunca la precede. En el derecho en cambio, tal confianza precede, certifica e incluso constituye la prueba. Luego, lo que observamos aquí no es un estándar probatorio sino una excusa para condenar o absolver ${ }^{77}$.

\footnotetext{
${ }^{71}$ Cfr. Ibid., p. 51.

${ }^{72}$ Cfr. Accatino, D. "El modelo legal de justificación...”, cit., p. 137.

${ }^{73}$ Cfr. Ibid., p. 138.

${ }^{74}$ Cfr. Ferrer, J. Prueba y verdad en el derecho, Editorial Marcial Pons, Madrid, 2002, p. 75.

${ }^{75}$ Cfr. Ibíd., p. 22.

${ }^{76}$ Cfr. Ferrer, J. Valoración racional de..., cit., pp. 144-145-146.

${ }^{77}$ Cfr. Laudan, L. “Porque un estándar de prueba...”, cit., pp. 105-106.
} 


\subsection{Principales consecuencias de un estándar de prueba subjetivo}

Esta interpretación del estándar probatorio "más allá de toda duda razonable” priva al mismo de su función normativa al entenderlo como una mera remisión al estado mental del juzgador. De este modo, queda mutilado el modelo de justificación de los enunciados probatorios, puesto que, aunque se acepte que existen criterios racionales para establecer la corroboración entre los elementos de prueba y los enunciados que buscan probar, la determinación de su suficiencia para tenerlos por probados queda abandonada a una suerte de revelación mística del juzgador ${ }^{78}$. Es decir, el juzgador tiene absoluta arbitrariedad para determinar cuándo se ha probado un hecho ${ }^{79}$. Luego, este estándar de prueba no se corresponde con el objetivo del proceso de la búsqueda de la verdad.

En directa relación con lo anterior, y como se señaló previamente, la noción subjetivista tiene como rasgo el vincular los enunciados declarativos de hechos probados con la convicción o la creencia del juez en la verdad de su ocurrencia. Esta idea afecta gravemente la exigencia de la fundamentación de la sentencia. Esto porque las creencias son algo que nos sucede, algo cuya ocurrencia no depende de nuestra voluntad, y como solo los actos voluntarios son susceptibles de justificación, no habría entonces posibilidad de justificar la valoración de la prueba realizada por el juez ${ }^{80}$. Es decir, "(s)i no está claro lo que es una duda razonable -y no lo está en absoluto- el acto de justificar un veredicto como algo más allá de toda duda razonable se convierte en un quijotesco ejercicio de autoengaño" 81 .

Por último, la formulación subjetiva de este estándar de prueba entra en conflicto con el art. 297 del CPP. Debido a que este estándar opera de acuerdo con el estado mental del juzgador, en tal sentido el juzgador condenará o absolverá de acuerdo a su sola convicción sobre la ocurrencia de la comisión del delito. Sin embargo, el art. 297 del CPP, señala que es obligatorio el análisis de la prueba en conformidad a las reglas de la lógica, conocimientos científicamente afianzados y máximas de la experiencia. De tal forma, si aplicando dichos criterios de evaluación debiera concluirse que un enunciado está probado los jueces debieran aceptar dicho enunciado como probado con independencia de su convicción. Ahora bien, entre ambas normas no existen relaciones ordenadoras por lo cual estaríamos en presencia de una contradicción que se traduciría en que ante un mismo caso dos soluciones incompatibles son admisibles ${ }^{82}$.

\footnotetext{
${ }^{78}$ Cfr. Accatino, D. "Forma y sustancia en el razonamiento probatorio. Alcance del control sobre la valoración de la prueba a través del recurso de nulidad penal", Revista de Derecho PUCV XXXII, Ediciones Universitarias de Valparaíso, 2009, Valparaíso, p. 358.

${ }^{79}$ Cfr. Aguilera, E. "Crítica a la "convicción íntima" como estándar de prueba en materia penal”, Reforma Judicial. Revista mexicana de Justicia, instituto de investigaciones jurídicas UNAM, N 12, México D.F, p. 6.

${ }^{80}$ Cfr. Accatino, D. "La fundamentación de la declaración...", cit., p. 20.

${ }^{81}$ Cfr. Laudan, Larry: "Una breve réplica”, DOXA: Cuadernos de filosofía del Derecho, $\mathrm{N}^{\circ} 28$, Madrid, 2005, p. 154.

${ }^{82}$ Cfr. Coloma, Rodrigo: "Panorama general de la prueba...", cit., p. 26-27.
} 
En consecuencia, se hace necesaria una reforma legislativa del art. 340 del CPP que consagre un estándar de prueba en términos objetivos. Ya que en un sistema en donde cada juez utiliza un criterio diferente, no podemos esperar ni uniformidad ni justicia en las decisiones de los tribunales ${ }^{83}$.

\section{CONClusiones}

En el proceso penal, debido a la gravedad de las consecuencias jurídicas que éste supone, parece especialmente importante que la determinación de la efectividad de la acusación sobre la base de las pruebas rendidas en juicio pueda aproximarse en la mayor medida posible a la verdad de los hechos que esta contiene. Así, en esta manifestación del proceso, las instituciones que rigen la actividad probatoria deben permitir el mayor grado de corroboración posible entre lo que se declara probado con lo que realmente ha ocurrido.

La presunción de inocencia es un Derecho Fundamental que le asiste a toda persona. Derecho que si bien no se reconoce expresamente en nuestra Constitución, sí se consagra en diversos tratados internacionales, los cuales en virtud del art. $5^{\circ}$ inc. $2^{\circ}$ de nuestra Carta Fundamental son incorporados a nuestra legislación transformándose en un límite a la soberanía del Estado, debiendo ser respetados y promovidos por todos sus órganos.

En el ámbito probatorio, la presunción de inocencia supone que el resultado de esta actividad valorativa deba ser explicitado en la sentencia, toda vez que mediante la motivación de la decisión será posible determinar si las pruebas rendidas en el juicio logran destruir dicha presunción. Ahora bien, esta valoración si bien es libre de acuerdo a lo prescrito por el art. 297 del CPP, no supone que el juez se encuentre exento de reglas a las que atenerse y decida según criterios que no se puedan valorar intersubjetivamente, es por esto que el mismo artículo previamente citado impone determinados límites a la valoración, a saber, las máximas de la experiencia, las reglas de la lógica y los conocimientos científicamente afianzados. Es decir, solo cabe un modelo de valoración racional de la prueba. Y esto no puede ser de otra manera debido a que el derecho a la presunción de inocencia impone un mandato de interdicción de la arbitrariedad, actuando como barrera para la actuación autoritaria del juez, toda vez que lo que se presume es que el acusado es inocente de los hechos que se le acusan. Luego, para destruir la presunción de inocencia, la prueba rendida por la Fiscalía debe ser valorada de forma objetiva y racional para que de tal forma dicho razonamiento pueda ser plasmado en la sentencia, sirviendo como un elemento de control de la actividad jurisdiccional, impidiendo de esta forma que el juzgador prive de la libertad a una persona por su mera voluntad.

Para determinar cuánta prueba es necesaria para tener por acreditado un hecho, el Derecho dispone del instrumento procesal denominado estándar de prueba. Las funciones más relevantes del estándar de prueba se pueden resumir en tres. Primero, permite

${ }^{83}$ Cfr. Laudan, Larry: Truth, Error and... cit., p. 31. 
establecer el nivel de suficiencia necesaria para que el juez pueda tener por acreditado la ocurrencia de un hecho y en tal sentido es una herramienta orientada hacia la averiguación de la verdad. Segundo, es un mecanismo que permite distribuir los errores judiciales en la declaración de hechos probados. Estos errores se traducen en condenas falsas y absoluciones falsas. Y tercero, cumple una función justificadora de la decisión probatoria, la cual obliga al juez a explicitar en la motivación de la sentencia si se cumplen o no los presupuestos establecidos por el estándar probatorio para sobrepasar el umbral de suficiencia necesaria que permite declarar un hecho como probado.

Esta función de umbral permite determinar cuándo la presunción de inocencia es superada y se hace posible la condena del acusado. Luego, transforma al estándar de prueba en una garantía del derecho a la presunción de inocencia, protegiendo a los ciudadanos de una condena irracional y arbitraria por parte del juzgador, pues solo a la luz de los elementos de una valoración racional de la prueba rendida en juicio será posible determinar cuándo se ha sobrepasado el estándar de prueba, legitimando de esta forma, el uso del poder punitivo estatal traducida en la sentencia que declara culpable al acusado y la consiguiente aplicación de la pena correspondiente. Luego, la decisión del juzgador sobre la condena debe ser motivada, en el sentido de que se permita recrear los razonamientos seguidos por este para determinar si se ha sobrepasado el estándar de prueba y por ende si se ha derrotado la presunción de inocencia, impidiendo de esta forma condenar por la sola voluntad del Tribunal.

Ahora bien, solo si la formulación del estándar de prueba se realiza en términos objetivos y exigentes, se podrán alcanzar el cumplimiento de las funciones previamente descritas y pueda cumplir el rol de garantía de la presunción de inocencia. Además, el estándar de prueba así formulado permite alcanzar el objetivo de la averiguación de la verdad que le asiste al proceso, toda vez que al establecer un alto nivel de exigencia para la superación de este, permite un mayor grado de precisión en la determinación de la verdad sobre la ocurrencia de los hechos objetos del juicio.

Sin embargo, el estándar de prueba "más allá de toda duda razonable" consagrado en nuestro ordenamiento jurídico en el art. 340 del CPP, carece de los elementos necesarios para cumplir las funciones propias de tal institución. Primero debido a la extrema vaguedad de su formulación, no establece el umbral de suficiencia sobre el cual el juez tendrá el parámetro para poder declarar un hecho por probado, de tal forma, no permite determinar cuándo la presunción de inocencia ha sido superada. Además, al no establecer los parámetros sobre los cuales el juez deba cotejar su decisión de tener por probado un hecho, este estándar de prueba se hace incompatible con el fin de averiguación de la verdad que le cabe al proceso. Segundo, es de naturaleza difusa y subjetiva, toda vez que se remite al estado mental del juzgador, en términos de convicción/duda, y, como estos estados subjetivos varían de persona en persona y, con frecuencia, en la misma persona de tiempo en tiempo, no pueden servir como condición suficiente para determinar la corrección de los juicios de prueba. Ahora bien, como las creencias son algo que nos sucede, su ocurrencia es independiente de nuestra voluntad, y como sólo los actos voluntarios son susceptibles de justificación, no habría entonces posibilidad de justificar la valoración de la prueba realizada por el tribunal, ergo no es posible la fundamentación 
de la sentencia. Por último, al no hacer posible la motivación de la sentencia, el juez no puede dar las razones de por qué se superó la presunción de inocencia, abriendo una puerta a la arbitrariedad en la decisión judicial y en tal sentido vulnera el mandato de interdicción de la misma exigido por el derecho a la presunción de inocencia.

Se concluye entonces, que el estándar probatorio "más allá de toda duda razonable" consagrado en el art. 340 inc. $1^{\circ}$ del CPP, es de naturaleza subjetiva, el cual vulnera el derecho a la presunción de inocencia al fallar en su rol de garantía del mismo, siendo incompatible además, con el fin de la averiguación de la verdad en el proceso penal. Luego, la falta de un estándar de prueba formulado en términos objetivos posibilita la arbitrariedad judicial en el proceso penal haciendo de dudosa utilidad todos los derechos y garantías del proceso penal, toda vez que la etapa más importante de este, el momento de decisión de absolución o condena, queda entregado a un acto arbitrario del juez, que por su propia naturaleza no puede ser controlada.

\section{BIBLIOGRAFÍA}

Accatino, D., "La fundamentación de la declaración de hechos probados en el nuevo proceso penal. Un diagnóstico", en Revista de Derecho Universidad Austral de Chile, Vol. XIX, No 2, 2006, pp. 9-26.

Accatino, D., "Forma y sustancia en el razonamiento probatorio. Alcance del control sobre la valoración de la prueba a través del recurso de nulidad penal", Revista de Derecho PUCV XXXII, Ediciones Universitarias de Valparaíso, 2009, Valparaíso, pp. 347-362.

Accatino, D., "El modelo legal de justificación de los enunciados probatorios en las sentencias penales y su control a través del recurso de nulidad", en Accatino, D. (coordinadora), Formación y valoración de la prueba en el proceso penal, LegalPublishing, Santiago, 2010, pp. 119-143.

Aguilar, M., La presunción de inocencia, Iter criminis $N^{\circ} 8$, tercera época, noviembre-diciembre/2006, México D.F., pp. 9-29.

Aguilera, E., "Crítica a la 'convicción íntima' como estándar de prueba en materia penal", Reforma Judicial. Revista Mexicana de Justicia, Instituto de Investigaciones Jurídicas UNAM, $\mathrm{N}^{\circ}$ 12, México D.F., pp. 3-16, 2008.

Belda, E., "La presunción de inocencia”, Parlamento y Constitución, Anuario N ${ }^{\circ}$, Ciudad Real, 2001, pp. 179-204.

Coloma, R., "Panorama general de la prueba en el juicio oral chileno", en Coloma C., R. (editor), La prueba en el nuevo proceso penal, LexisNexis, Santiago, 2003.

Coloma, R., "Estándares de prueba y juicios por violaciones a los Derechos Humanos". Revista de Derecho Universidad Austral de Chile ACH, Vol. XXII-No 2,2009, pp. 205-222.

Colombo, J., "Garantías constitucionales del debido proceso penal. Presunción de inocencia". Anuario de derecho constitucional latinoamericano 2007, edición UNAM, México DF, pp. 345-369.

Fernández, M., Prueba y presunción de inocencia, editorial Iustel, Madrid, 2005.

Ferrajoli, L., Derecho y razón, Editorial Trotta, Madrid, 1995.

Ferrer, J., Prueba y verdad en el derecho, editorial Marcial Pons, Madrid, 2002.

Ferrer, J., Valoración racional de la prueba, editorial Marcial Pons, Madrid, 2007.

Ferrer, J., "La prueba es libertad, pero no tanto. Una teoría de la prueba cuasi-Benthamiana en Accatino, D. (coordinadora), Formación y valoración de la prueba en el proceso penal, LegalPublishing, Santiago, 2010.

Gascón, M., Los hechos en el Derecho, Editorial Marcial Pons, Madrid, 1999. 
Gascón, M., "Sobre la posibilidad de formular estándares de prueba objetivos", DOXA: Cuadernos de Filosofía del Derecho, No 28, Madrid, 2005, pp. 128-139.

GoZAínI, O., "La presunción de inocencia del proceso penal al proceso civil", Revista Latinoamericana de Derecho,No 6,UNAM, México D.F., pp. 155-179.

Igartua, J., "Motivación de las sentencias, presunción de inocencia 'In dubio pro reo'”, Anuario de Derechos Humanos, Universidad Complutense de Madrid, No 2, Madrid, 2001.

"Informe de la Comisión Mixta”, en Historia de la Ley 19.696 que establece el Código Procesal Penal, con fecha 12 de octubre del año 2000, Chile.

Jara, J., "Principio de inocencia. El estado jurídico de inocencia del imputado en el modelo garantista del proceso penal”., Revista de Derecho Universidad Austral de Chile, Vol. X, No especial reforma procesal penal, 1999, pp. 41-58.

LAUDAN, L., "Porque un estándar de prueba subjetivo y ambiguo no es un estándar", DOXA: Cuadernos de Filosofía del Derecho, No 28, Madrid, 2005, pp. 95-113.

Laudan, L., "Una breve réplica”, DOXA: Cuadernos de filosofía del Derecho, No 28, Madrid, 2005, pp. 151-155.

Laudan, L., Truth, Error and Criminal Law, an essay in legal epistemology, Cambridge University Press, Reino Unido, 2006.

Luzón, J., La presunción de inocencia ante la casación, editorial Colex, Madrid, 1991.

López, J., "Debido Proceso en Chile: hacia un principio generador de reglas", en Bordalí, A. (coordinador), Justicia Constitucional y Derechos Fundamentales, LexisNexis, Santiago, 2006.

Nogueira, H., "Consideraciones sobre el Derecho Fundamental a la presunción de inocencia", Revista Ius est Praxis, Talca, Vol. 11, N 1, 2005, pp. 221-241.

Nogueira, H., "La reforma constitucional del 2005 y control de constitucionalidad de los tratados internacionales", Estudios Constitucionales: Revista del Centro de Estudios Constitucionales, Talca, Año 5, No 1, 2007, pp. 59-88.

Pedrajas, A., "Derecho a la presunción de inocencia y proceso de trabajo", Derecho Privado y Constitución, No 4, Madrid, 1994, pp. 223-272.

Pfeffer, E., "Los tratados internacionales sobre Derechos Humanos y su ubicación en el orden normativo interno", Revista Ius et Praxis, Talca, Vol. 9, No 1, 2003, pp. 467-484.

Romero, E., La presunción de inocencia: Estudio de algunas consecuencias de la Constitucionalización de este Derecho Fundamental, Editorial Aranzadi, Madrid, 1981.

TAdros, V., "Rethinking the presumption of innocence", Criminal law and philosophy, Vol. 1, issue 3, Springer Science + Business Media B.V, Netherlands, 2007, pp. 193-213.

TARuffo, M., "Consideraciones sobre prueba y verdad", en Coloma, R. (Coordinador), La prueba en el nuevo proceso penal, LexisNexis, Santiago, 2003, pp. 163-184.

Taruffo, M., "Algunos comentarios sobre la valoración de la prueba”, Discusiones: Prueba y conocimiento, $\mathrm{N}^{\circ} 3$, Madrid, 2003, pp. 81-97.

TARuffo, M., "Tres observaciones sobre "porque un estándar de prueba subjetivo y ambiguo no es un estándar' de Larry Laudan”, DOXA: Cuadernos de Filosofía del Derecho, No 28, Madrid, 2005, pp. 115-126.

TAruffo, M., Simplemente la verdad, Editorial Marcial Pons, Madrid, 2010.

Tavolari, R., Instituciones del nuevo proceso penal, cuestiones y casos, Editorial Jurídica de Chile, Santiago, 2005.

TOMÁs y VALIENTE, F., “ «In dubio pro reo», libre apreciación de la prueba y presunción de inocencia”, Revista española de Derecho Constitucional, año 7, N²0, mayo/agosto, Madrid, 1987, pp. 9-34.

VÁzQuez, J., Presunción de inocencia del imputado e "intima convicción" del tribunal (estudios sobre la utilización del imputado como fuente de prueba en el proceso penal español), Editorial Bosch, Madrid, 1984. 
